NBER WORKING PAPERS SERIES

\title{
BUSINESS CYCLE DURATIONS AND POSTWAR STABILIZATION OF THE U.S. ECONOMY
}

Mark W. Watson

Working Paper No. 4005

\author{
NATIONAL BUREAU OF ECONOMIC RESEARCH \\ 1050 Massachusetts Avenue \\ Cambridge, MA 02138 \\ March 1992
}

This paper is an extension of my discussion of Diebold and Rudebusch (1991), presented at the NBER Economics Fluctuations meeting in July 1991, and I thank the authors for stimulating my interest in this area. I would also like to thank Robert Gordon, Robert King, Jeff Miron, Glenn Rudebusch, and colleagues at the Chicago Federal Reserve Bank for useful comments and suggestions. Special thanks go to Jim Stock for detailed suggestions, to Robert Gordon, Jeff Miron and Christina Romer for making data available, and to Edwin Denson for excellent research assistance. This work was supported by National Science Foundation grant no. SES89-10601. This paper is part of NBER's research programs in Economic Fluctuations and Monetary Economics. Any opinions expressed are those of the author and not those of the National Bureau of Economic Research. 
NBER Working Paper \#4005

March 1992

\title{
BUSINESS CYCLE DURATIONS AND POSTWAR STABILIZATION \\ OF THE U.S. ECONOMY
}

\begin{abstract}
The average length of business cycle contractions in the United States fell from 20.5 months in the prewar period to 10.7 months in the postwar period. Similarly, the average length of business cycle expansions rose from 25.3 months in the prewar period to 49.9 months in the postwar period. This paper investigates three explanations for this apparent duration stabilization. The first explanation is that shocks to the economy have been smaller in the postwar period. This implies that duration stabilization should be present in both aggregate and sectoral output data. The second explanation is that the composition of output has shifted from sectors that are very cyclical, like manufacturing, to sectors that are less cyclical, like services. This would lead to increased stability in aggregate output even in the absence of increased stability in the individual sectors. The third explanation is that the apparent stabilization is largely spurious, and is caused by differences in the way that prewar and postwar business cycle reference dates were chosen by the NBER. The evidence presented in this paper favors this third explanation.
\end{abstract}

\author{
Mark W. Watson \\ Department of Economics \\ Northwestern University \\ Evanston, IL 60208 \\ and NBER
}




\section{Introduction}

A key piece of evidence supporting the efficacy of aggregate demand management is the observation that, on average, postwar business cycles in the United States have been less severe than in the prewar period. This argument, presented by Burns (1960) and subsequently investigated by other researchers, has been seriously challenged in a series of papers by Romer (1986a, 1986b, 1989, 1991). ${ }^{1}$ Romer's argument is that the apparent stability of the postwar economy is largely an artifact of measurement error in the prewar data, which spuriously increases its volatility. However, much of the evidence supporting the contention of postwar stabilization has not relied on the volatility in specific series, but instead on the duration of business cycles calculated using the historical reference dates determined by researchers at the National Bureau of Economic Research (NBER). These duration data suggest that the average length of recessions has fallen dramatically in the postwar period: from $1854-1929$ contractions averaged 20.5 months, while from 1945.1990 they averaged 10.7 months; similarly over the same periods, prewar expansions averaged 25.3 months, while postwar expansions averaged 49.9 months. Diebold and Rudebusch (1991) show that these prewar-postwar differences are statistically highly significant and robust to many of the changes in NBER business cycle chronology debated in the historical literature.

This paper investigates three explanations for this apparent stabilization of the postwar economy. The first explanation is that shocks to individual sectors of the economy were smaller in the postwar period than in the prewar period. This may reflect a fortuitous exogenous change in the process generating shocks, or it may reflect effective government policy dampening the effects of exogenous shocks. The empirical analysis reported below offers little support for this explanation.

The second explanation is that the cyclical behavior of individual sectors was the same in the prewar and postwar periods, but that changes in the relative importance of the sectors led to 
changes in the cyclical behavior of the aggregate economy. For example, the service sector has traditionally been less cyclical than the manufacturing sector, and over time has grown in importance relative to the manufacturing sector. Once again, the empirical analysis offered below does not support this explanation.

The third explanation is that the differences in durations are spurious, caused by systematic biases in the information used to form the reference dates. The empirical analysis presented in this paper supports this explanation. In particular, the analysis suggests that the paucity of prewar data forced early NBER researchers to focus their attention on a small number of economic time series, and these series represent sectors of the economy that are systematically more volatile than aggregate activity. This exaggerated volatility reflected itself in longer contractions and shorter expansions in the prewar period.

The remainder of this paper presents evidence on the relative plausibility of these three explanations. In Section 2, contraction and expansion durations in "specific cycles" of individual series are investigated to see if these have changed across the prewar and postwar period. Little evidence of change is found in the individual series. Section 3 , which investigates the effect of the changing composition of output on the durations of the business cycle, suggests that changing composition cannot explain the differences between the prewar and postwar durations. Section 4 reviews the construction of the prewar reference dates and compares the data used to date prewar business cycles with the data used to date postwar cycles. This analysis suggests that the prewar business cycle chronology relied on data with a much narrower focus than the data used to date postwar cycles. When postwar cycles are dated using data similar to that used to date prewar cycles, little difference between the prewar and postwar periods is evident. Some concluding comments are offered in the final section. 


\section{Phase Durations of Specific Series}

The questions raised in the introduction can only be resolved by comparing prewar and postwar data, and as Romer's work shows, extreme care must be exercised in such a comparison: the series used must be of consistent quality (either good or bad) across the prewar and postwar period. Data availability enforces a tradeoff between coverage and sampling interval. The available annual data cover many sectors of the economy, but are far from ideal for business cycle analysis, since annual data can mask short or mild contractions. Monthly data are more useful, but there are few monthly series of consistent quality spanning a significant portion of the prewar and postwar period. In this section both monthly and annual data are used to uncover prewar-postwar changes in the average phase durations of "specific cycles" associated with these series.

Identifying specific cycles in economic time series requires a precise definition of a "contraction" and an "expansion." Unfortunately, the definition of contraction and expansion used by the NBER is too vague for this purpose. ${ }^{2}$ This paper uses an objective definition embedded in an algorithm developed by Bry and Boschan (1973). ${ }^{3}$ This algorithm is a set of $a d$ hoc filters and rules that determine business cycle turning points in an economic time series. Essentially, the algorithm isolates local minima and maxima in a time series, subject to constraints on both the length and amplitude of expansions and contractions. For many series, the 3 ry-Boschan algorithm does a remarkably good job at reproducing the turning points selected by "experts." For example, Chart 1 shows monthly values of pig iron production from 1877-1929. The horizontal lines on the graph are the turning points selected by the BryBoschan procedure; the arrows point to the turning points selected by Burns and Mitchell (1946). ${ }^{4}$ Little difference between the Bry-Boschan and Burns and Mitchell peaks and troughs is evident.

Consistent with practice at the NBER, the Bry-Boschan algorithm dates contractions and expansions using the level of the series, rather than the detrended series. Thus, contractions 
correspond to sequences of absolute declines in a series, and not to periods of slow growth relative to trend: the algorithm dates "business cycles" and not "growth cycles." This will be important when interpreting the changes in prewar and postwar average phase durations for series that experienced a significant change in their trend rate of growth. Changes in trend rates of growth have obvious effects on contraction and expansion lengths: decreases in average growth rates lead to increases in average contraction duration and decreases in average expansion duration.

Table 1 shows average phase durations calculated using the Bry-Boschan dating algorithm for a variety of monthly prewar and postwar series. For many of these series the prewar and postwar data are not perfectly comparable, and comparisons using a variety of postwar series are presented. To eliminate any effect of the Great Depression, the prewar period is truncated in 1929 , although the substantive conclusions offered below are unaltered if the period is extended to 1940 . For each series the table presents the average length of contractions $(\overline{\mathcal{C}}$, and the average length of expansions $(\bar{E})$ in the prewar and post war period. As discussed above, since contractions are defined as absolute declines, rather than declines below trend growth, average annual growth rates $\left(\vec{X}=\right.$ sample mean of $\left.\left(\log \left(x_{t}\right)-\log \left(x_{t-12}\right)\right)\right)$ over the two sample periods are shown, as are the t-statistic for testing the null hypothesis of no change in the growth rate $(t \bar{X})$. In addition. the standard deviation of the annual growth rates $(\sigma)$ for the prewar and postwar periods are shown together with the ratio of prewar to postwar standard deviations. Finally, the table presents the Wilcoxon rank sum statistic $\left(W_{c}\right.$ and $\left.W_{E}\right)$ for comparing the prewar and postwar contraction and expansion phase durations. The statistic is presented in standardized form and can be interpreted like a t-statistic for a significant change in the average duration. ${ }^{5}$ (For example, absolute values greater than 2 are statistically significant.)

A serious problem with the monthly data is that there are few direct indicators of output or employment; many of the series are from the financial sector and are imperfect indicators of sectoral or aggregate output. The first panel of the table shows results for a variety of financial 
series. In summary, real stock prices show little change in cyclical behavior, long term interest rates show a slight increase in the length of postwar expansions with little change in the length of contractions, and commercial paper rates show a decrease in postwar contraction duration and increase in expansion duration. ${ }^{6}$ For these series the only statistically significant change is for commercial paper expansions. The other financial series - business failures, stock exchange volume and bank clearings - show large changes in trend growth rates, which makes it difficult to compare the prewar and postwar duration average durations.

Panel B presents results for production indicators. The first set of comparisons involve prewar pig iron production and postwar industrial production indices for metals and steel. In the postwar period, contractions are longer and expansions shorter, but this reduction is undoubtedly related in part to the decline in the growth rate of this sector. The next comparison involves prewar railroad freight ton-miles and postwar manufacturers shipments. Again, the rapid growth in the prewar period makes this comparison difficult. The final, and potentially most informative comparison, involves the prewar industrial production index constructed in Miron and Romer (1990) and postwar industrial production indices. Comparing the Miron-Romer series to postwar aggregate index of industrial production suggests results very similar to the NBER phase durations for expansions: postwar expansions are roughly twice as long as prewar expansions. While this comparison is tempting, it turns out to be inappropriate because the $\mathrm{mix}$ of goods in the Miron-Romer series differs significantly from the mix of goods in the aggregate IP index. To control for the mix of goods in the index, the final row of the table compares the Miron-Romer index to a postwar index with approximately the same product mix. ${ }^{7}$ This postwar index has remarkably similar cyclical properties as the Miron-Romer index. Panel $\mathrm{C}$ contains two comparisons involving prices and construction. Prices are difficult to compare because of changes in trend behavior. There appears to be little change in the average contraction and expansion durations for construction.

Table 2 presents results for annual data. The complications of the Bry-Boschan dating algorithm are not needed for annual data: contractions are defined as sequences of absolute 
declines in the series, and expansions are defined as sequences of absolute increases. The top panel of the table shows results for various measures of aggregate activity. The first two rows are for the GNP series constructed by Romer (1989) and by Balke and Gordon (1989). Both series show a slight decrease in the average length of contractions in the postwar period; for Romer's series average contraction duration decreases by 1 years and for the Balke-Gordon series by 3 years in the postwar period. For both series, average postwar expansions are shorter than their prewar counterparts. The Romer and Balke-Gordon prewar series are based in large part on Shaw's (1947) commodity output series. This series accounts for between one third and one half of real GNP during the prewar period. The results for Shaw's commodity output are shown in row 3 of the table. The results for this series are similar to those for GNP: postwar contractions and expansions are slightly shorter than their prewar counterparts. The next row presents results for annual industrial production: the prewar data is the series constructed by Frickey (1947) and the postwar data is Romer's (1986b) extension of Frickey's series. This serics shows a significant break in trend, making comparison of the postwar and prewar phase durations difficult. Finally, the last row in the panel considers Romer's (1986a) unemployment data. For this series, postwar contractions are shorter and expansions longer than in the prewar, but the differences are not great: 2 years for contractions, 11 years for expansions. In summary the aggregate annual data show little evidence of dramatic differences in prewar and postwar cyclical behavior.

Panels B-D present results for individual sectors of the economy. The series are from Romer (1991a), and they were chosen because they satisfy the requirement of consistent quality through the entire sample period. ${ }^{8}$ The results for these series are summarized in the bottom panel of the table, which compares the frequencies of series for which average expansion and contraction lengths increased in the postwar period to the frequencies for which they decreased. These are presented for series without significant changes in trend growth rates. The summary table suggests that there is a tendency for postwar contractions to be longer than prewar contractions, and for postwar expansions to be shorter than prewar expansions. 
Taken together, the annual data provide little support for the notion that contractions are shorter and expansions longer in the postwar period. An important caveat is, that while this may accurately reflect the cyclical behavior of these series, it may also reflect the limitations of using annual data to analyze phase durations.

Three conclusions emerge from these data. First, they suggest that there has been little change in the average phase durations of sectoral output. This is evident from the annual data. in which many sectors were considered, and in the monthly data which considered pig iron production and a fixed weight index of industrial production. The second conclusion is that these results carry over to aggregate series also. This is evident from the annual data on GNP and unemployment and the monthly data on stock prices. Third, while average phase durations do not seem to have changed, there is evidence that volatility has decreased. This is easily seen in Table 2, which presents the ratio of the standard deviation for growth rates for prewar and postwar data. A reduction in variability can also be seen for many of the monthly series.

These conclusions are tempered by three caveats: first, the monthly data are very limited; second, the annual sectoral data represent production of commodities and there is no data on the other sectors of the economy; finally, the prewar annual GNP series are less representative of the aggregate economy than the postwar series because of measurement problems documented in Balke and Gordon (1989) and Romer (1989).

\section{Sectoral Changes}

One potential explanation for the reduced cyclicality in the postwar period is the changing composition of aggregate output. This explanation is discussed in some detail in Zarnowitz and Moore (1986), who document the increasing importance of "less cyclical" relative to "more cyclical" sectors in the postwar period. Table 3 presents some related evidence. It shows the historical evolution of sectoral shares of total employment together with postwar average phase durations of sectoral employment. During the postwar period, the more cyclical sectors - 
manufacturing, transportation, communications and public utilities, and mining - grew more slowly than the less cyclical sectors. Most notable is the share of manufacturing (a highly cyclical industry) which fell from $34.7 \%$ of nonagricultural employment in 1948 to $17.3 \%$ in 1990 , and the share of service employment (a very noncyclical sector), which rose from $11.5 \%$ in 1948 to $25.6 \%$ in 1990 . This increase in the share of employment in noncyclical sectors suggests a reduction in the cyclicality of aggregate employment, even in the absence of changes in the individual sectors.

However, some of the data in the table suggests that sectoral composition may not explain the differences between the prewar and postwar periods. In particular, the table shows that growth rates within sectors have changed significantly through time. For example, manufacturing employment grew at an average rate of $2.4 \%$ from $1869-1929$, and only $0.4 \%$ from 1948-1990. Since downturns are measured as absolute declines in a series and not declines relative to trend, this suggests that manufacturing was less cyclical in the prewar period (when it had a larger trend) than in the postwar period (when it had a smaller trend). Thus, even though manufacturing accounted for a smaller share of aggregate employment in the postwar period it may have been more cyclical. Thus, the trends in sectoral employment paint an ambiguous picture of aggregate cyclicality in the prewar and postwar data.

If monthly prewar employment data were available, it would be possible to model changes in stochastic process governing sectoral employment across the prewar and postwar periods, and to deduce implications for the changing cyclical properties of aggregate employment. Unfortunately, the only reliable prewar sectoral employment data are from the decennial census. These data can be used to estimate trends, but by themselves provide little information about the cyclical properties of the series. This makes it impossible to identify all of the prewarpostwar changes in the sectoral employment processes that affect the cyclicality in aggregate employment.

However, since the trends in the prewar data can be estimated, it is possible to determine how the differences in prewar and postwar employment trends affect the average phase 
durations. This can be done by assuming that the only difference in the stochastic process generating the prewar and postwar data is the difference in trend behavior. This is an extreme. but useful assumption, since it allows the analysis to focus on the cyclical impact of the employment trends shown in table 3. The assumption will be relaxed below, when other potential changes in sectoral employment are investigated.

The cyclical impact of the trends in the data can be determined as follows. First, for each sector, models for the trend are estimated for both the prewar and postwar periods. The prewar trend model is estimated using the decennial census data, and the postwar trend model is estimated using monthly data available from the BLS Establishment Survey. The postwar monthly data are then detrended, and the resulting series is used to estimate a model for the shortrun variability and interaction of the sectoral data. This shortrun model is then appended to the estimated prewar model for the trends to produce a model for the prewar monthly data. Thus, the prewar and postwar models differ only in their implications for the trend behavior of the data; they share the same model for shorter run movements in the data. The cyclical properties of the resulting employment series from the prewar and postwar models can then be deduced.

The results from implementing this procedure are shown in Tables $4 a$ and $4 b$. In table $4 a$. the trends for each sector are estimated by regressing the logs of the data on a constant and time trend. The prewar regressions used decennial data from $1869-1929$ and the postwar regressions used monthly data from 1948-1990. In table 4b, more flexible trends were estimated by allowing for kinks in the trend line every twenty years; in the prewar period kinks were allowed in 1889 and 1909 and in the postwar period a kink was allowed in 1968:1. In both cases the shortrun model was estimated as a VAR(4) using the detrended logarithms of the monthly postwar data. The resulting prewar and postwar models were then used to generate pseudo monthly employment data for the 1869-1929 and $1948-1990$ periods, the Bry-Boschan algorithm was used to date business cycles in the resulting aggregate employment data, and 
average contraction and expansion lengths were calculated for the realizations. This data generation process was repeated 500 times and the resulting average phase durations are reported in the table.

The results suggest three observations. First, there is very little difference between the average phase durations across the two tables: the results from the broken trend model are very similar to the fixed trend model. Second, the generated postwar data have average phase durations very similar to the actual postwar aggregate employment data, and these in turn are similar to the average phase durations of NBER dated business cycles. Third, the generated prewar data have average contraction lengths similar to the postwar data and average expansion lengths over one year longer than the postwar data. This suggests that the underlying trend behavior in the sectoral employment data would be expected to lead to less cyclical behavior in the prewar period than in the postwar period.

These observations are reinforced by percentiles of the empirical distributions from the 500 replications corresponding to the prewar and postwar NBER dated business cycles. These percentiles are shown in parentheses in the tables. For example. looking at the postwar phase durations, 14 percent of the realizations from the postwar single trend model had average contraction lengths less than 10.7 months (the average duration of NBER dated postwar contractions), and 38 percent of the realizations had average expansion lengths shorter than 49.9 months (the average duration of postwar NBER dated expansions). The percentiles in the table indicate that the average phase durations for the postwar NBER dated business cycles are consistent with the trend-VAR model used to generate the data, but that the NBER prewar dated business cycles are not consistent with the model.

Thus far, the analysis has focused on trends, but other characteristics of the sectoral employment stochastic process may explain the differences in the prewar and postwar phase durations. For example, shocks may have been more highly correlated across sectors in the prewar period. This would tend to increase the variance in the aggregate employment series 
and potentially make it more cyclical. ${ }^{9}$ Alternatively, sectoral employment may have been more volatile in the prewar period. Unfortunately, since high frequency prewar employment data are not available, it is impossible to statistically investigate these potential explanations. However, it is possible to experiment with modifications of the model characterizing the postwar data, for example doubling the correlation between the shocks, to find out what kinds of modifications are required to explain the prewar phase durations.

While the VAR(4) fits the data well, it is not well suited for these experiments since it allows complicated dynamic interaction between the eight sectors. This makes it difficult to isolate the characteristics of the process which are responsible for the phase durations. Instead of using VAR, the experiments are carried out using a dynamic factor model of the form

(5.1) $x_{t}^{i}=\alpha_{i} f_{t}+u_{t}^{i}$

(5.2) $\mathrm{f}_{\mathrm{t}}=\phi_{1} \mathrm{f}_{\mathrm{t}-1}+\phi_{2} \mathrm{f}_{\mathrm{t}-2}+\mathrm{e}_{\mathrm{t}}$

(5.3) $u_{t}^{i}=\rho_{i} u_{t-1}^{i}+\epsilon_{t}^{i}$

where $x_{t}^{i}$ is the detrended level of log employment in the $i$ 'th sector at time $t, f_{t}$ is a scalar "common factor," $e_{t}$ and $\epsilon_{\mathrm{t}}^{\mathrm{i}}$ are zero mean white nose processes with variances $\sigma_{\mathrm{e}}^{2}$ and $\sigma_{\epsilon}^{2} \mathrm{i}$ respectively, and $E\left(e_{t} \epsilon_{\tau}^{i}\right)=E\left(\varepsilon_{t}^{j} \epsilon_{\tau}^{i}\right)=0$ for all $i, t, \tau$ and $i \neq j$. In this model, all of the dynamic interaction in the sectors comes through the common factor $f_{t}$. The "uniquenesses," $u^{i}$, are uncorrelated across sectors and allow each sector to move independently of the other scctors.

This model was fit to the detrended postwar data and the results are shown in Table 5a. The results look sensible. The most cyclical sectors - mining construction and manufacturing - have the largest values of $\alpha$, indicating the largest amount of covariation. The least cyclical sectors - government, services and F.I.R.E. - have the smallest values of $\alpha$. The common factor, $f_{t}$, and each of the uniqueness, $u_{v}^{i}$ are highly persistent with exact or near unit autoregressive roots. ${ }^{10}$ 
Pseudo prewar and postwar data were generated by appending the dynamic factor model onto the models for the prewar and postwar trends. ${ }^{11}$ The results from 500 realizations of the processes are shown in the first two rows of Table $4 b$. This model produces data with average contraction lengths similar to the trend-VAR model, but with somewhat longer a verage expansions. The remaining rows of the table show results for modifications of the dynamic factor model. For example, in the third row of the table, the model was modified by multiplying each of the factor loadings by $/ 2$ and reducing the variance of the uniquenesses by an offsetting amount. This doubles the correlation between the sectors while leaving the variance of each sector unchanged. This modification lengthens average contraction and shortens average expansions, but not nearly enough to explain the prewar NBER data. In the next three rows the factor loadings are increased by varying amounts and the uniqueness variances are unaltered. The results suggest that a dramatic increase in the covariance of the sectors is necessary to explain the results: the factor loadings need to be increased by a factor of 5 , which corresponds to an increase in the covariance of the sectors by a factor of 25 . This modification has a dramatic effect on the variability of the data - the standard deviation of the annual growth rate in the aggregate pseudo prewar data is over 5 times larger than the postwar data.

This section suggests two conclusions about the effect of changes in the composition of employment on prewar and postwar cyclicality. First, differences in the trend rate of growth across sectors do not explain the differences in the prewar and postwar average phase durations. Second, very dramatic, and implausibly large changes in the covariance structure of the prewar and postwar employment data are necessary to explain the prewar average phase durations.

\section{Biases in the Prewar Data}

The results from sections 2 and 3 suggest that there is little in the data to support the claim that the postwar period has witnessed a reduction in the duration of cyclical contractions and an increase in the duration of cyclical expansions. Why is such a change evident in the NBER 
business cycle chronology? One explanation is that NBER researchers chose the prewar reference dates in a way that fundamentally differed from the way that the postwar reference dates were chosen. Two possibilities suggest themselves. First, the relative paucity of prewar data suggests that NBER researchers may have chosen reference dates for the prewar period using data that were systematically more cyclically volatile than the aggregate economy, and as more data became available, this defect was corrected in the postwar period. This would imply that the apparent postwar stabilization is due to the changing composition of series used to date the cycle; it is not due to changes in the cyclical behavior of individual series or to changes in the composition of aggregate output or employment. The second possibility is that the prewar data may have been processed differently than the postwar data. For example, the prewar may have been detrended while the postwar data was not.

To investigate the merits of these possibilities it is useful to review the procedure that NBER researchers used to determine the prewar reference dates. ${ }^{12}$ The prewar chronology was chosen judgementally based on both quantitative and qualitative information. The qualitative information consisted in large part of the "business annals" collected in Thorpe (1926). These annals are a summary of contemporaneous reports that appeared in the business and popular press; for the U.S. they cover the period 1790-1925. The Thorpe annals provided an initial set of reference dates, which were then refined by examining available monthly, quarterly and annual time series.

The quantity and quality of these data improved dramatically over the sample period covered. For example, only 19 monthly or quarterly series were available in $1860 ; 8$ of these were price series, 8 were financial variables and only 3 were related to production - hog receipts in Chicago, cattle receipts in Chicago and shoe shipments from Boston. By 1930 the availability of data had changed dramatically: 710 monthly and quarterly series were available and 245 of these related to production and personal incomes ${ }^{13}$. Aggregate employment and production indices played no role in the dating of the early cycles. Monthly data on aggregate 
nonagricultural employment did not become available until 1929, although an index of factory employment extended back to $1914{ }^{14}$ The earliest monthly index of industrial production used by Burns and Mitchell extended back to $1904 .{ }^{15}$ Monthly and quarterly estimates of personal income and gross and net national product did not exist for the pre-1920 period. Burns and Mitchell list 46 monthly and quarterly series available before $18900^{16}$ of these 10 are indirect indicators of business activity, such as the volume of bank clearings, 4 are orders for durable goods or construction, 2 are production indicators, 15 are price indices or price series, 9 are financial indicators such as stock prices and interest rates, and 4 are indicators of business failures. Many of these series were included in the monthly indicators included in Table 1.

Unfortunately the historical record does not provide a detailed description of how Thorpe's qualitative data were combined with the available statistical data to determine the prewar reference dates. Romer (1991b) provides a very useful summary of the historical record. She has traced the pre-1927 reference dates back to an NBER news bulletin dated March 1, 1929 that was apparently written by Mitchell, but the document contains little specific guidance about how the dates were determined. On the other hand, Mitchell's 1927 book, Business Cycles: The Problem and its Setting, contains a detailed discussion of Thorpe's Annals and the available statistical data that could potentially be used for choosing reference dates.

Romer (1991b) points out that two time series, the A.T.T. business index and Snyder's clearing index, receive particular attention in the discussion in Mitchell's 1927 book. The A.T.T. index begins in 1877 , and is a combination of data series meant to measure general business activity. From 1877 to 1884 it was based solely on pig iron production; bank clearing outside New York City and blast furnace capacity were added in 1885 and wholesale prices were added in 1892 (Mitchell (1927), page 294). Snyder's clearing index begins in 1875 , and is based on bank clearings outside New York City deflated by a price index. As stressed by Romer, the key characteristic of both of these series is that they are presented as deviations from trends, rather than levels. Thus, if these series influenced the choice of prewar dates, they could impart a "growth cycle" bias in the prewar business cycle chronology. 
An estimate of the magnitude of this bias can be calculated by comparing the average phase durations for levels and detrended levels of pig iron production and bank clearings, the most important components of the A.T.T. business index and Snyder's clearing index. The average phase durations for the levels were given above in Table 1 . As would be expected, the detrended series had longer average contractions and shorter average expansions than the series in levels. But the differences were not large. For pig iron production, the difference was 2.4 months for contractions (12.9 versus 15.3 ) and 4.9 months for expansions (28 versus 23.1). For bank clearings, contractions were 2.8 months shorter (16.2 versus 1.34) and expansions 6 months longer (18.9 versus 24.9 months) using the detrended data. ${ }^{17}$ To put these differences into perspective, recall that the postwar contractions are an average of 9.8 months shorter than prewar contractions and postwar expansions are an average of 24.6 months longer than prewar expansions. Thus, while the use of the detrended A.T.T. business index and Snyder's clearing index may have biased the average phase durations, these biases are small compared to differences in the prewar and postwar average phase durations.

An alternative explanation of the differences in the average prewar and postwar durations, is that the data used to date the prewar cycles was systematically more volatile than aggregate activity, and that this bias was eliminated in the postwar period. A simple way to investigate this explanation is to date postwar business cycles using only those indicators that were used to date the prewar cycles. That is, to "Romerize" the postwar reference dates by artificially restricting the postwar data to be as limited as the prewar data.

Table 6 presents peak and trough dates for seven series covering the same range of activities as the 46 series available to Burns and Mitchell. The notable deletions from the list is any consideration of bank clearing and prices, because of the change in the drift in these series shown in Table 1. Moreover, I have not attempted to construct a postwar annals, analogous to that constructed by Thorpe. ${ }^{18}$

Evident in the table is a clustering of "specific cycles" for the individual series, consistent with the notion of the business cycle. While the Bry-Boschan algorithm determines turning 
points in individual series, it does not solve the multivariate problem of determining a "reference cycle" from a collection of series. Here, I have used judgement based on the turning points in the individual series to construct a set of reference dates. These are shown in the table along with the NBER reference dates. In selecting the reference dates, I assumed that the two production indices were coincident indicators; that is, on average, they moved contemporaneously with the cycle. When specific cycles in these series approximately coincided, I averaged the peak and trough dates. For each production index there were specific cycles that did not correspond with movements in other series, and these were ignored when choosing the reference dates. Panel B of the table shows the reference dates that I selected along with the lead-lag relations of the individual indicators. These suggest reasonable conformity across cycles. ${ }^{19}$

These pseudo reference dates suggest a much more volatile postwar period than the NBER reference dates. They suggest three more recessions (1951:4-1952:1, 1966:1-1967.6 and 1984:41986:1), longer contractions and shorter expansions. ${ }^{20}$ Summary statistics comparing average phase durations from these pseudo reference dates to the NBER prewar and postwar chronologies are presented in panel $\mathrm{C}$ of the table. These data suggest little change in the length of expansions across the prewar and postwar periods and a reduction in the length of contractions that is only one half as great as suggested by the NBER chronology. Moreover, neither of the changes is statistically significant.

\section{Concluding Remarks}

This paper has investigated three explanations for the postwar duration stability evident in the NBER business cycle chronology. Little support is found for explanations that lead to duration stability across individual sectors of the economy: for most individual series, average contraction and expansion durations for the prewar and postwar periods are similar. Thus, there is little evidence that more effective demand management in the postwar period has led to 
increased duration stability. The data also cast doubt on the changing composition of output and employment as the cause of the apparent postwar stability. Historical differences in trend growth rates of sectoral employment explain little of the observed changes in average duration. An explanation that is consistent with the data is that the prewar NBER business cycle chronology was determined by data that, at least in the postwar period, are systematically more volatile than the aggregate economy. Thus, selection bias in the data series available to researchers in the prewar period appears to be the most likely explanation for the postwar duration stability apparent in the NBER data.

Two points should be kept in mind when interpreting these conclusions. First, these results concern only the duration of contractions and expansions and say nothing about their amplitude. A more meaningful answer to the question of postwar stability may hinge on relative amplitudes or volatilities rather than on durations. The data summarized in Tables 1 and 2 suggest an increase in the volatility of most of the series studied. Second, these results should not be viewed as a criticism of the work summarized in Burns and Mitchell (1946). These authors were careful to point out the limitations of their reference dates. ${ }^{21}$ Their primary interest was not in the reference dates and the lengths of cycles, but in how individual series moved over the cycle. No analysis has been offered in this paper to address the robustness of their finding in this regard to changes in the prewar chronology. 
1. Also see Bailey (1978), Zarnowitz and Moore (1986), Delong and Summers (1986) and Balke and Gordon (1986).

2. Burns and Mitchell (1946) give the official definition of contractions and expansions. These are phases of the business cycle, which they defined as:

"Business cycles are a type of fluctuation found in the aggregate economic activity of nations that organize their work mainly in business enterprises: a cycle consists of expansions occurring at about the same time in many economic activities, followed by similarly general recessions. contractions, and revivals which merge into the expansion phase of the next cycle; this sequence of changes is recurrent but not periodic; in duration business cycles vary from more than one year to ten or twelve years; they are not divisible into shorter cycles of similar character with a mplitude approximating their own."

Historically, phases for specific series and business cycle reference dates have been determined judgementally.

3. The Bry and Boschan programs are described and applied in a novel and interesting way in King and Plosser (1989).

4. The Burns and Mitchell dates are from Chart 53, page 373.

5. See Lehmann (1975) for a general discussion of the statistic and Diebold and Rudebusch (1991) for a discussion in the context of tests for business cycle phase durations. The standardized form of the statistic shown in the table is asymptotically standard normal. (Its exact sampling distribution can also be deduced.) In large samples, a standard t-test can also be used to compare the average durations. For the data considered here, the results using a standard t-test are similar to the results using the $W$ statistics.

6. Shapiro (1988) examines prewar and postwar stock price volatility and finds no significant difference between the periods.

7. This postwar index is a weighted average of industrial production indices for metals, mining, food, apparel products, and rubber and plastics. It is fully described in the data appendix. The Miron-Romer index for the prewar period is composed primarily of materials as opposed to products. Materials account for approximately $40 \%$ of the postwar IP and products account for the remaining $60 \%$. The materials and product components have markedly different average phase durations in the postwat period: the materials component of industrial production has average contraction and expansion durations of 14.8 months and 31.1 months, respectively; the corresponding values for the products component is 14.7 months and 57.7 months.

8. I thank Christina Romer for supplying me with these data.

9. Steve Davis suggested this potential explanation.

10. Diagnostic tests, checking the statistical adequacy of the model, are not presented.

Undoubtedly, these tests would suggest that the model is too restrictive and is not an adequate statistical description of the postwar data. This should not be too troubling: the purpose of the estimated model is not to test a null hypothesis or to construct forecasts, circumstances in which the misspecification could be very important. Rather the estimated model is to serve as a benchmark for some experiments that will give some rough answers to questions about the prewar and postwar data. A careful analysis of these and related data postwar data using dynamic factor models in contained in Denson (1992). 
11. Results are shown for the broken trend models. Results for the single trend models are very similar.

12. More detailed and thorough reviews of the procedure can be found in Moore and Zarnowitz (1986), Diebold and Rudebusch (1991), Romer (1991b) and of course Burns and Mitchell (1946).

13. These data are from Burns and Mitchell (1946), table 17 and page 81, footnote 24.

14. Burns and Mitchell, page 74.

15. This was Babson's index of the physical volume of business, see Burns and Mitchell, page 73.

16. See Burns and Mitchell, table 21.

17. Romer (1991b) carries out a similar exercise using the Miron-Romer IP series over the $1884-1927$ period and a dating algorithm similar to the Bry-Boschan algorithm. She finds that contractions are 3.2 months longer using the detrended data and expansions are 3.4 months shorter.

18. My impression from reading the business press during the 1980's and 1990's is that a postwar annals would greatly overstate the cyclical variability of the economy.

19. An alternative approach to determining the reference dates is to extract a single factor from a dynamic factor model estimated using these data series. Turning points in this extracted factor could then be determined by the Bry-Boschan program. I experimented with this approach, but found it unsatisfactory. The results from this procedure depend critically on the variance of the factor relative to its average drift. Unfortunately, both the variance and drift are econometrically unidentified in a factor model and must be determined judgementally. I chose instead to apply judgement to the turning point data directly.

20. Each of these periods corresponded to a marked slowdown in economic activity as measured by the NBER experimental coincident index. These slowdowns were not severe enough to be regarded as recessions.

21. See, in particular Chapter 4 of Burns and Mitchell (1946). 


\section{References}

Bailey, M.N. (1978), "Stabilization Policy and Private Economic Behavior," BPEA, 1, 11-50.

Balke, N.S. and R.J. Gordon (1989), "The Estimation of Prewar Gross National Product: Methodology and New Evidence," Journal of Political Economy, 94, 38-92.

Bry, G. and C. Boschan (1971), Cyclical Analysis of Time Series: Selected Procedures and Computer Programs, New York; Columbia University Press for the NBER.

Burns, A. F. (1960), "Progress Towards Economic Stability," American Economic Review, 50, 1 19.

Burns, A. F. and W.C. Mitchell (1947), Measuring Business Cycles, New York: National Bureau of Economic Research.

Delong, J.B. and L. H. Summers (1986), "The Changing Cyclical Variability of Economic Activity in the United States,"in Robert J. Gordon (ed.), The American Business Cycle: Continuity and Change. Chicago: University of Chicago Press.

Denson, E.M. (1992), "An Analysis of Postwar Employment Data," forthcoming.

Diebold, F.X. and G.D. Rudebusch (1991), "Have Postwar Economic Fluctuations Been Stabilized?" manuscript, University of Pennsylvania.

Frickey, E. (1947), Production in the United States, 1860-1914. Cambridge, Mass: Harvard University Press.

Kendrick. John W. (1961), Productivity Trends in the United States, Princeton: Princeton University Press.

King, R.G. and C.I. Plosser (1989). "Real Business Cycles and the Test of the Adelmans," manuscript, University of Rochester.

Lehmann, E.L. (1975), Nonparametrics, San Francisco: Holden Day.

Miron, J.A. and C.D. Romer (1990), "A New Monthly Index of Industrial Production, 18841940," Journal of Econonic History, Vol. L, 321-337.

Mitchell, Wesley C. (1927), Business Cycles: The Problem and Its Setting, New York: National Bureau of Economic Research.

Moore, G.H. and V. Zarnowitz (1986), "The Development and Role of the NBER's Business Cycle Chronologies," in Robert J. Gordon (ed.), The American Business Cycle: Continuity and Change. Chicago: University of Chicago Press.

Romer, Christina D. (1986a) "Spurious Volatility in Historical Unemployment Data," Journal of Political Economy, 94, 1-37.

(1986b), "Is the Stabilization of the Postwar Economy a Figment of the Data?" American Economic Review', 76, 314-334.

(1989). "The Prewar Business Cycle Reconsidered: New Estimates of

Gross National Product, 1869-1908." Journal of Political Economy, 97, 1-37. 
(1991a), "The Cyclical Behavior of Individual Production Series, 1889

1894," Quarterly Journal of Economics, 106, 1-32.

(1991b), "Remeasuring Business Cycles: A Critique of the Prewar NBER Reference Dates," manuscript, U.C. Berkeley.

Shapiro, M.D. (1988), "The Stabilization of the U.S. Economy: Evidence from the Stock Market," American Economic REview, 78, 1067-1079.

Shaw, William H. (1947), The Value of Commodity Output Since 1869, New York: NBER.

Thorpe, Willard L. (1926), Business Annals. National Bureau of Economic Research, New York.

Zarnowitz, V. and G.H. Moore (1986), "Major Changes in Cyclical Behavior," in Robert J. Gordon (ed.), The American Business Cycle: Continuity and Change. Chicago: University of Chicago Press. 


\section{Data Appendix}

This appendix describes the prewar and postwar data used in the paper. A11 of the postwar data, unless otherwise noted are from Citibase. All of the prewar data, unless otherwise noted are from the NBER Business Cycle Database.

\section{Prewar Data}

Annual Data:

The sources for annual data are given in the tables and the text.

Monthly Data:

Monthly Series:

Pig Iron Production

Rail Road Stock Prices

NYSE Volume

Bank Clearings

Business Failures

RR Bond Yields

Commercial Paper

Building Plans

RR ton-miles

Wholesale Price Index

Total Exports

Total Imports

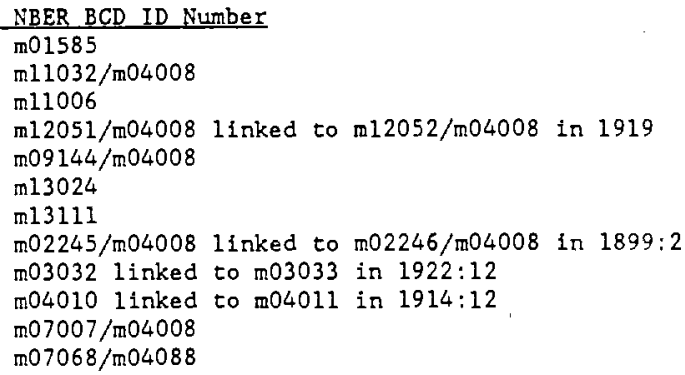

The S\&P and Dow Jones nominal stock prices are from Moore (1961). They were deflated by the NBER BCD series m04008 (an index of the general price leve1). The prewar monthly industrial series is from Miron and Romer (1990).

Transformations:

Many of the series required some preprocessing. In most cases this was to correct obvious coding errors in the NBER Business Cycle Database. The specific transformations were:

M01585:

10 was subtracted from the observation in 1880:11

Observations in 1926:1, 1928:1 and 1930:1 were multiplied by 10 .

M11032:

Missing values in 1872:4 and 1914:8-1914:11 were estimated by 1inear interpolation.

M13024:

Missing values in 1857:9-1857:10 were estimated by linear interpolation.

M02246:

Missing values in 1929:3:9-1929:4 were estimated by linear interpolation. The series was then seasonally adjusted using the RATS exponential moving average procedure. 
Miron and Romer Industrial Production:

The serles was then seasonally adjusted using the RATS exponential moving average procedure.

M03033

The series was then seasonally adjusted using the RATS exponential moving average procedure.

M07068:

Missing value in 1867:12 was estimated by linear interpolation.

Postwar

Annual Data:

The sources of annual data are given in the tables and the text.

Monthly Serles:

Description:

Industrial Production

Industrial Production, materials IPM

Industrial Production, products IPP

Industrial Production, metals IPDM2

Industrial Production, iron and steel IPDM3

Consumer Price Index

Manufacturers Shipments

Exports

Imports

$S \& P$ Industrials

$S \& P$ Transportation

S\&P Composite

Dow Jones Industrials

NYSE Volume

Corp. Bond Yield (AAA)

PUNEW

MFGS/PUNEW

F6TED/PUNEW

F6TMD/PUNEW

FSPIN/PUNEW

FSPTR/PUNEW

FSPCOM/PUNEW

FSDJ / PUNEW

FSVOL

FYAAAC

Ind. Bond Yield (AAA)

FYAAAI

Corp. Bond Yield (BAA)

FYBAAC

Ind. Bond Yield (BAA)

FYBAAI

Commercial paper rate FYCP

Business Failures FAIL

Producer Prices

Bullding Permits

PW

Total Nonag Employment

HSBP

Construction Employment LPCC

Manufacturing Employment LPEM

F.I.R.E. Employment LPFR

Mining Employment LPMI

Government Employment LPGOV

Service Employment LPS

Wholesale and Retail Trade Emp. LPT

Trans, and Pub. Util. Emp. LPTU 
Bank Clearings: debits (demand deposits) at other than NY banks is from the Federal Reserve Bulletin. The nominal values were deflated by the CPI (Citibase series PUNEW).

The Postwar Approximation to the Miron-Romer Index of Industrial Production: The approximate Miron-Romer IP series for the postwar period is calculated as:

IPMR - wmet*ipdn2+wmin*ipmin+wfood*ipnfo2+wapp*ipnt3+wrub*ipnch5/w

where:

whe $t=31.91+2.13$

wfood $=2.53+5.42+7.76+9.28+2.18$

wmin $=9.92+2.54+3.85$

wapp $-11.89+4.62$

wrub $=5.97$, and

$w=w m e t+w$ food $+w m i n+w r u b+w a p p$

Whet represents the composite weight in Miron and Romer given to (i) Pig Iron Capacity, and (ii) Tin Imports.

wfood represents the composite weight in Miron and Romer given to (i) Sugar Meltings at Four Ports, (ii) Cattle Recelpts in Chicago, (iii) Hog Receipts in Chicago, (iv) Minneapolis Flour Shipments, and (v) Coffee Imports.

Wmin represents the composite weight in Miron and Romer given to (i) Anthracite Coal Shipments, (ii) Connellsville Coke Shipments, and (iii) Crude Petroleum Products, Appalachian Region.

Wapp represents the composite weight in Miron and Romer given to (i) wool Receipts at Boston, and (ii) Raw Silk Imports.

Wrub represents the composite weight in Miron and Romer given to Crude Rubber Imports.

Transformations:

LPTU:

An outlier in 1983:8 was replaced with a linearly interpolated value.

LPMI :

This series was adjusted for outliers as follows. First the trends was removed from the logarithm of the series using a Hodrick-Prescott filter. Second, extreme observations (greater 3 standard deviations) were set equal to the mean. Finally, this adjusted series was then added to HodrickPrescott trend and the series was exponentiated.

F6TED:

The series was then seasonally adjusted using the RATS exponential moving average procedure.

F6TEM:

The series was then seasonally adjusted using the RATS exponential moving average procedure. 
Table 1

Average Phase Durations, Monthly Data

\begin{tabular}{|c|c|c|c|c|c|c|c|c|c|}
\hline Series & Sample & Period & $\overline{\boldsymbol{X}}$ & 0 & $\bar{C}$ & $\bar{E}$ & $t_{\bar{x}}$ & $w_{c}$ & $W_{E}$ \\
\hline \multicolumn{10}{|l|}{ A. FINANCLAL MARKETS } \\
\hline RR Stock Index & 1860:1 & $1929: 12$ & 1.67 & 14.73 & 20.1 & 25.9 & & & \\
\hline S\&P Industrials & 1947:1 & $1990: 12$ & 3.49 & 16.14 & 17.9 & 25.4 & -0.5 & 0.1 & -0.4 \\
\hline S\&P Transportation & 1970:1 & $1990: 12$ & 1.97 & 21.70 & 21.3 & 29.0 & 0.2 & -0.3 & -0.3 \\
\hline S\&P Composite & 1871:1 & 1929:12 & 1.79 & 15.19 & 17.9 & 24.9 & & & \\
\hline S\&P Composite & $1947: 1$ & $1990: 12$ & 3.08 & 15.67 & 17.3 & 25.9 & -0.4 & -0.2 & -0.5 \\
\hline Dow Jones Ind. & $1897: 1$ & $1929: 12$ & 4.07 & 20.85 & 17.9 & 22.7 & & & \\
\hline Dow Jones Ind. & 1947:1 & $1990: 12$ & 2.20 & 16.04 & 21.2 & 26.7 & 0.4 & 0.7 & -1.3 \\
\hline Bus. Failures & 1894:1 & $1929: 12$ & 0.40 & 49.73 & 29.3 & 30.9 & & & \\
\hline Bus. Failures & 1948:1 & 1990:9 & 9.20 & 44.66 & 15.9 & 28.8 & -0.9 & 2.4 & 0.1 \\
\hline NYSE Volume & 1875:1 & 1929:12 & 5.75 & 52.06 & 19.1 & 19.1 & & & \\
\hline NYSE Volume & 1947:1 & $1990: 12$ & 11.79 & 28.91 & 14.7 & 37.4 & -0.7 & 1.1 & -1.6 \\
\hline RR Bond Yields & $1857: 1$ & 1929:12 & -0.05 & 1.76 & 18.8 & 22.2 & & & \\
\hline Corp. Bond Yields (AAA) & 1947:1 & $1990: 12$ & 0.16 & 0.97 & 21.9 & 29.4 & -0.8 & -0.9 & -0.1 \\
\hline Ind. Bond Yields (AAA) & 1947:1 & 1990:12 & 0.16 & 0.93 & 21.0 & 30.3 & -0.8 & -0.4 & -0.4 \\
\hline Corp. Bond Yields (BAA) & 1947:1 & $1990: 12$ & 0.17 & 1.09 & 24.7 & 28.1 & -0.8 & -1.5 & -0.5 \\
\hline Ind. Bond Yields (BAA) & $1947: 1$ & $1990: 12$ & 0.18 & 1.04 & 22.1 & 30.9 & -0.9 & -0.9 & -1.0 \\
\hline Com. Paper Rate & $1857: 1$ & $1929: 12$ & -0.04 & 0.34 & 29.1 & 24.9 & & & \\
\hline Com. Paper Rate & 1947:1 & $1990: 12$ & 0.16 & 1.91 & 18.3 & 35.0 & -0.6 & 1.4 & -2.1 \\
\hline Bank Clearings & $1875: 1$ & 1929:12 & 3.56 & 7.25 & 13.4 & 24.9 & & & \\
\hline Bank Clearings & 1970:1 & $1990: 12$ & 8.93 & 6.69 & 13.0 & 117.0 & -2.4 & -0.8 & -1.9 \\
\hline \multicolumn{10}{|l|}{ B. PRODUCTION INDICATORS } \\
\hline Pig Iron Prod. & $1877: 1$ & $1929: 12$ & 6.08 & 30.78 & 12.9 & 28.0 & & & \\
\hline IP Metals & 1947:1 & 1990:12 & 1.00 & 20.16 & 19.2 & 22.7 & 0.9 & -1.7 & 0.9 \\
\hline IP Iron and Steel & 1947:1 & $1990: 12$ & 0.16 & 27.14 & 19.8 & 22.1 & 1.0 & -1.7 & 1.0 \\
\hline RR Freight ton-miles & $1866: 8$ & $1929: 12$ & 6.60 & 10.48 & 12.3 & 38.9 & & & \\
\hline Man. Shipments & 1947:1 & $1990: 12$ & 2.25 & 6.89 & 14.5 & 33.8 & 2.6 & -1.0 & 0.5 \\
\hline
\end{tabular}


Table $1-$ (Continued)

\begin{tabular}{|c|c|c|c|c|c|c|c|c|c|}
\hline Series & Sample & e Period & $\bar{X}$ & $\sigma$ & $\bar{C}$ & $\bar{E}$ & $t_{\bar{x}}$ & $W_{\mathrm{C}}$ & $W_{E}$ \\
\hline $\begin{array}{l}\text { IP-Miron/Romer } \\
\text { IP } \\
\text { IP-Miron/Romer (App) }\end{array}$ & $\begin{array}{l}1884: 1 \\
1947: 1 \\
1947: 1\end{array}$ & $\begin{array}{l}1929: 12 \\
1990: 12 \\
1990: 12\end{array}$ & $\begin{array}{l}4.53 \\
3.65 \\
1.76\end{array}$ & $\begin{array}{r}16.59 \\
6.26 \\
10.01\end{array}$ & $\begin{array}{l}10.8 \\
13.1 \\
13.9\end{array}$ & $\begin{array}{l}23.0 \\
50.3 \\
22.4\end{array}$ & $\begin{array}{l}0.3 \\
0.9\end{array}$ & $\begin{array}{l}-1.3 \\
-0.8\end{array}$ & $\begin{array}{r}-2.1 \\
0.3\end{array}$ \\
\hline \multicolumn{10}{|l|}{ c. ForEIGN TRADE } \\
\hline $\begin{array}{l}\text { Exports } \\
\text { Exports }\end{array}$ & $\begin{array}{l}1856: 7 \\
1977: 1\end{array}$ & $\begin{array}{l}\text { 1929:12 } \\
1990: 12\end{array}$ & $\begin{array}{l}4.37 \\
2.89\end{array}$ & $\begin{array}{l}19.90 \\
11.38\end{array}$ & $\begin{array}{l}13.4 \\
20.3\end{array}$ & $\begin{array}{l}27.9 \\
29.3\end{array}$ & 0.3 & -0.4 & -0.5 \\
\hline $\begin{array}{l}\text { Imports } \\
\text { Imports }\end{array}$ & $\begin{array}{l}1866: 7 \\
1977: 1\end{array}$ & $\begin{array}{l}1929: 12 \\
1990: 12\end{array}$ & $\begin{array}{l}3.85 \\
3.30\end{array}$ & $\begin{array}{r}21.07 \\
9.48\end{array}$ & $\begin{array}{l}17.2 \\
20.0\end{array}$ & $\begin{array}{l}33.0 \\
32.0\end{array}$ & -0.1 & -0.6 & 0.3 \\
\hline \multicolumn{10}{|l|}{ D. OTHER INDICATORS } \\
\hline $\begin{array}{l}\text { Wholesale Prices } \\
\text { Producer Prices }\end{array}$ & $\begin{array}{l}1890: 1 \\
1947: 1\end{array}$ & $\begin{array}{l}1929: 12 \\
1990: 12\end{array}$ & $\begin{array}{l}1.36 \\
3.52\end{array}$ & $\begin{array}{r}11.65 \\
4.92\end{array}$ & $\begin{array}{l}17.4 \\
13.1\end{array}$ & $\begin{array}{l}28.2 \\
50.1\end{array}$ & -1.1 & 1.3 & 0.1 \\
\hline $\begin{array}{l}\text { Plans for New Buildings } \\
\text { Building Permits }\end{array}$ & $\begin{array}{l}1868: 1 \\
1947: 1\end{array}$ & $\begin{array}{l}\text { 1929:12 } \\
1990: 12\end{array}$ & $\begin{array}{r}5.63 \\
-0.20\end{array}$ & $\begin{array}{l}73.66 \\
29.57\end{array}$ & $\begin{array}{l}16.6 \\
18.0\end{array}$ & $\begin{array}{l}19.1 \\
19.8\end{array}$ & 0.7 & -0.7 & -0.5 \\
\hline
\end{tabular}

Notes: $\bar{E}$ and $\bar{C}$, respectively denote average lengths of expansions and contractions (in months), $\bar{X}$ denotes the average annual growth rate in the series, $\sigma$ denotes the standard deviation of the annual growth rate, and $t_{\bar{X}}$ is the (autocorrelation robust) $t$-statistic for testing equality of growth rates across the two time periods. $W_{\mathrm{C}}$ and $\mathrm{W}_{\mathrm{E}}$ are the standardized Wilcoxon rank sum statistics for comparing the prewar and postwar durations of contractions and expansions, respectively. 


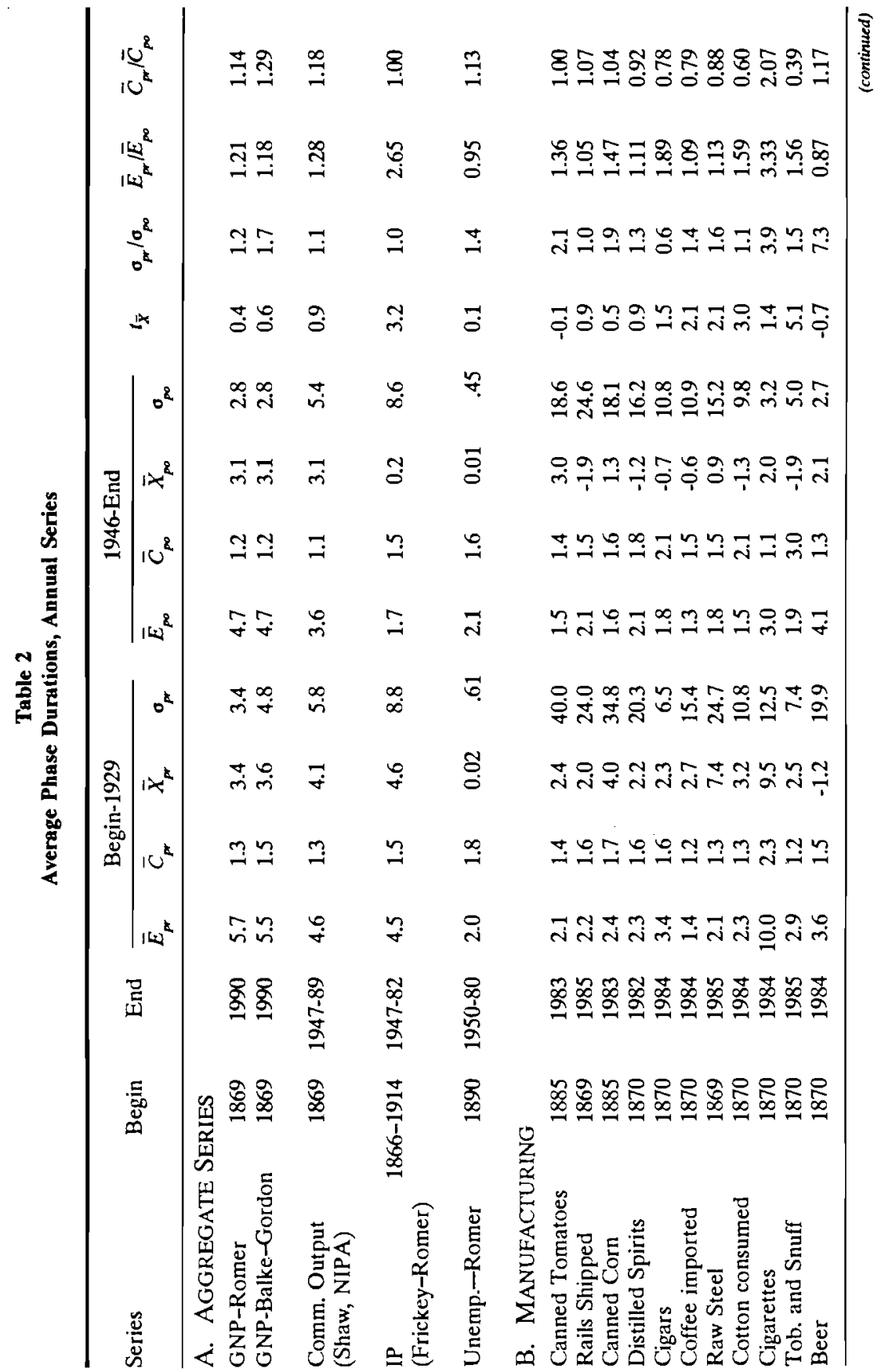




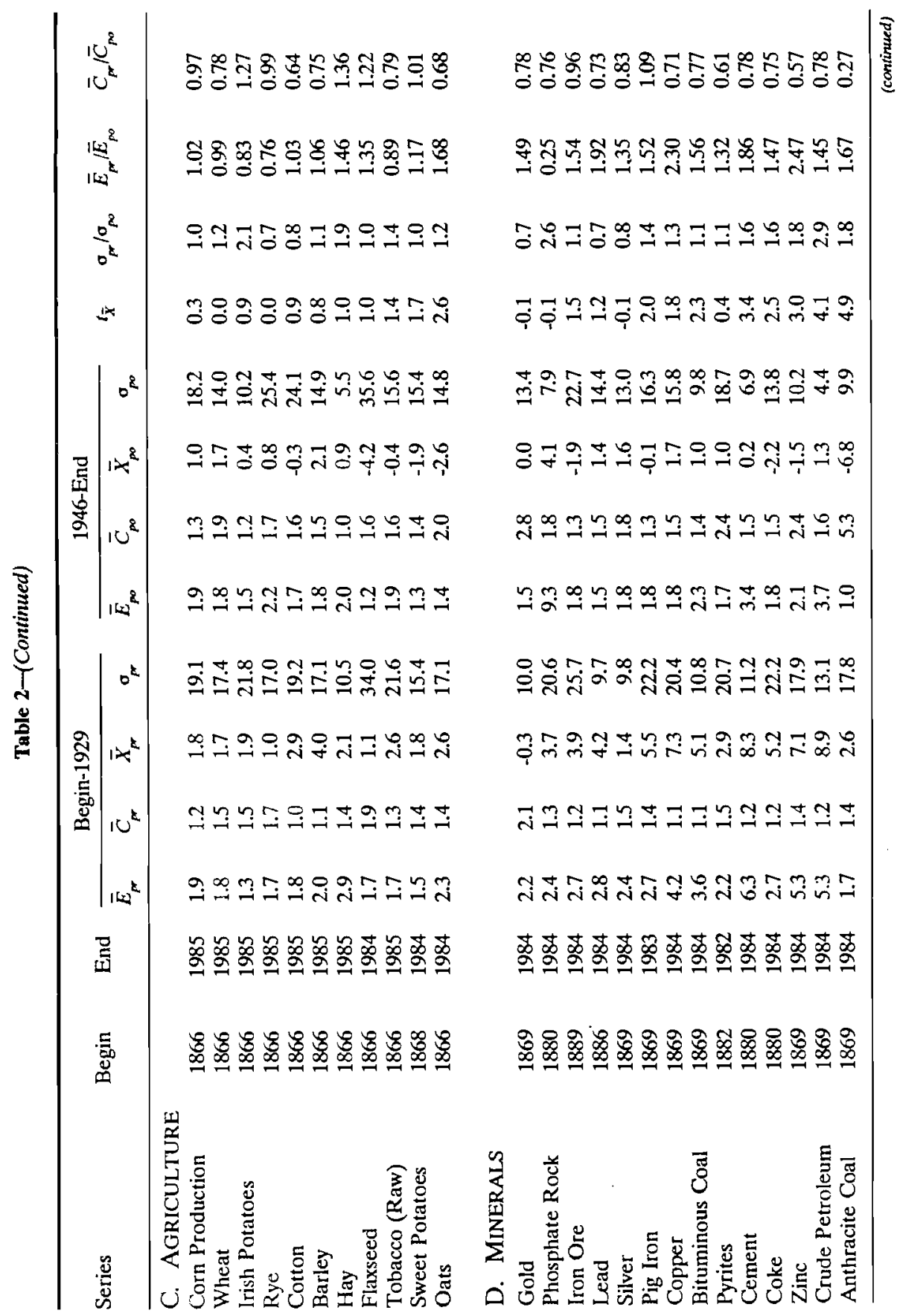




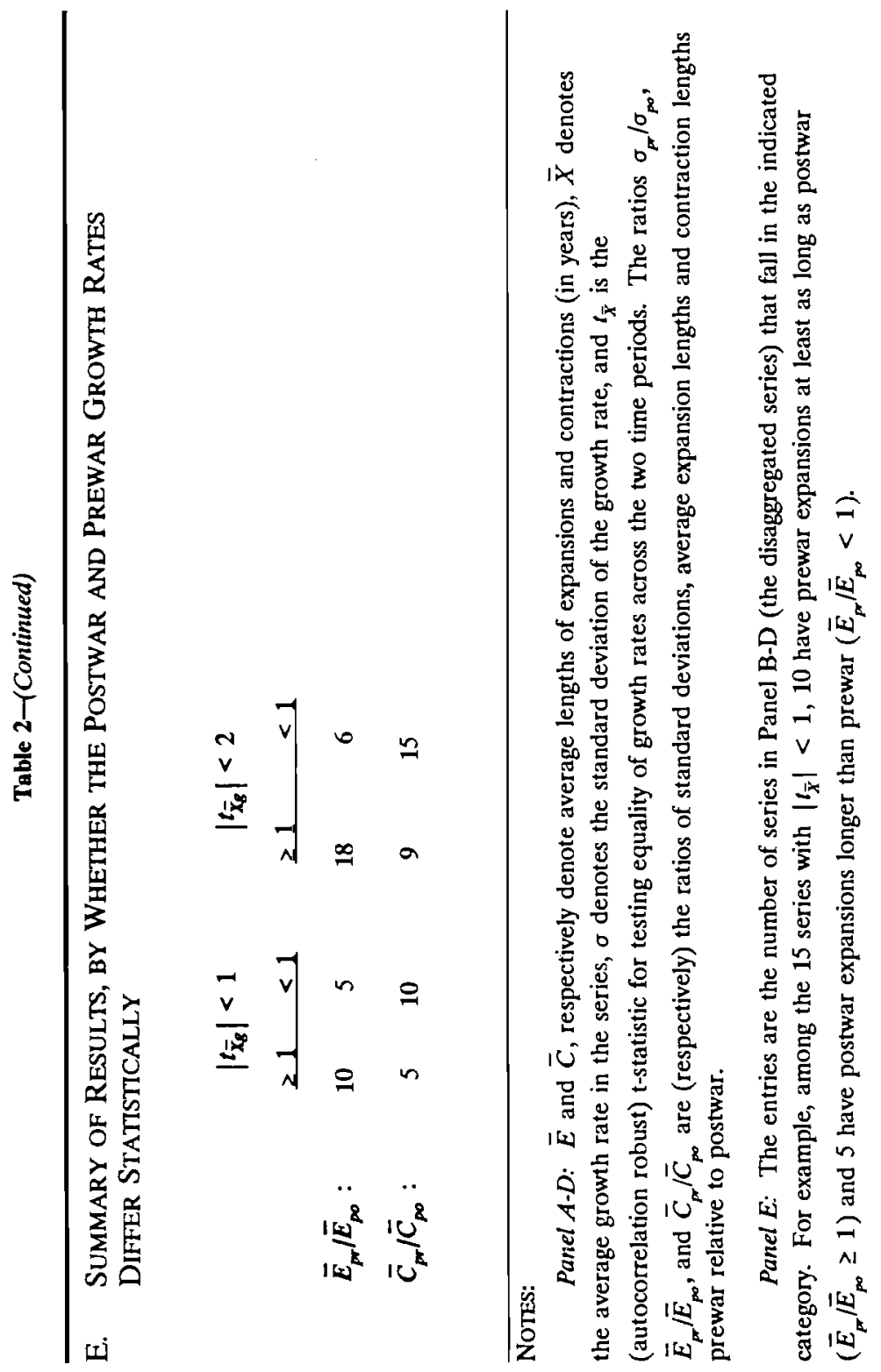




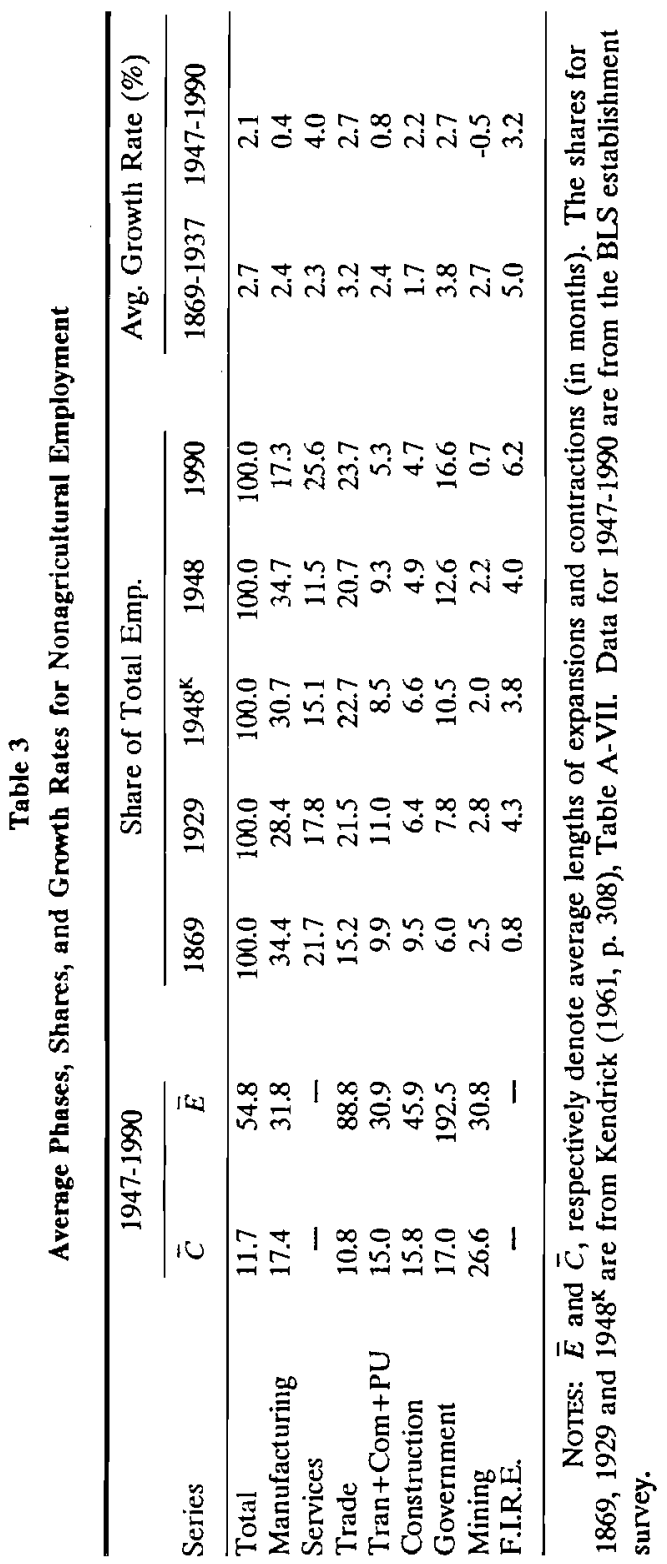




\section{Table 4}

Average Phases for Data Generated by the Trend.VAR Model

A. Single Prewar and Postwar Trends

\begin{tabular}{lccc}
\hline & $\bar{C}$ & $\bar{E}$ \\
\cline { 2 - 4 } Generated Data Prewar Trends & $11.9(.99)$ & $74.1 \quad(.00)$ \\
Generated Data Postwar Trends & $13.1(.14)$ & $57.6 \quad(.38)$ \\
Aggregate Postwar Employment & 11.7 & 54.8 \\
NBER Prewar & 21.2 & 26.5 \\
NBER Postwar & 10.7 & 49.9 \\
\hline
\end{tabular}

B. Trend Breaks Every 20 Years

\begin{tabular}{lll}
\hline & $\bar{C}$ & $\bar{E}$ \\
\cline { 2 - 3 } Generated Data Prewar Trends & $12.7(.99)$ & $70.0 \quad(.00)$ \\
Generated Data Postwar Trends & $13.5(.10)$ & $55.7(.39)$ \\
Aggregate Postwar Employment & 11.7 & 54.8 \\
NBER Prewar & 21.2 & 26.5 \\
NBER Postwar & 10.7 & 49.9 \\
\hline
\end{tabular}

NOTES: $\bar{E}$ and $\bar{C}$, respectively denote average lengths of expansions and contractions (in months). The numbers in parentheses are the percentiles of the distribution of average phase durations for the generated prewar and postwar data corresponding the NBER average phase durations. 
Table 5

Dynamic Factor Model

\section{A. Estimated Model}

$$
\begin{aligned}
& x_{t}^{i}=\alpha_{i} F_{t}+u_{t}^{i} \\
& u_{t}^{i}=\rho_{i} u_{t-1}^{i}+\epsilon_{t}^{i} \operatorname{Var}\left(\epsilon_{t}^{i}\right)=\sigma_{i}^{2} \\
& F_{t}=\phi_{1} F_{t-1}+\phi_{2} F_{t-2}+e_{t}, \operatorname{Var}\left(e_{t}\right)=1.0
\end{aligned}
$$

\begin{tabular}{lccc}
\hline Sector & $\alpha$ & $\sigma$ & $\rho$ \\
\hline Manufacturing & .0030 & .0044 & .97 \\
Services & .0006 & .0018 & .99 \\
Trade & .0012 & .0018 & .99 \\
Tran+Com+PU & .0016 & .0051 & .94 \\
Construction & .0029 & .0120 & .96 \\
Government & .0002 & .0036 & 1.00 \\
Mining & .0027 & .0179 & .99 \\
F.I.R.E. & .0004 & .0017 & 1.00 \\
& & & \\
\hline
\end{tabular}

B. Average Phases for Data Generated by the Trend-Dynamic Factor Model

1. Parameters from Estimated Model

Generated Data Prewar Trends

Generated Data Postwar Trends

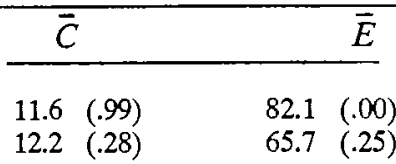

2. Prewar Results Using Modified Parameters

$\alpha_{i}$ Multiplied by $\sqrt{ } 2, \sigma_{i}^{2}$ reduced

$13.2(.99)$

$\alpha_{\mathrm{i}}$ Multiplied by $\sqrt{ } 2$

$13.1(.99)$

$\alpha_{i}$ Multiplied by 3

$16.3(.97)$

$31.1(.08)$

$\alpha_{\mathrm{i}}$ Multiplied by 5

$18.2(.82)$

$26.6 \quad(.40)$

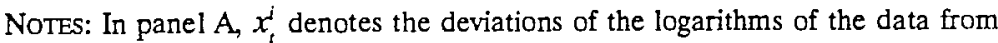
trend. The trend is of the form $\lambda_{0}+\lambda_{1} t+\lambda_{2} t(I(t>\tau))$, where I(.) is the indicator function and $r$ is 1967:12. The model was estimated using data from 1947:1-1990:12. The restriction $\operatorname{Var}\left(e_{i}\right)=1$ is a normalization that serves to identify the $\alpha_{i}$. In Panel $B$ the numbers in parentheses are the percentiles of the empirical distribution corresponding to the NBER average phase durations. In the first row of Panel B.2, $\sigma_{i}^{2}$ is reduced by $\alpha_{i}^{2}$, so that the variance of $x_{t}^{i}$ is unchanged. 


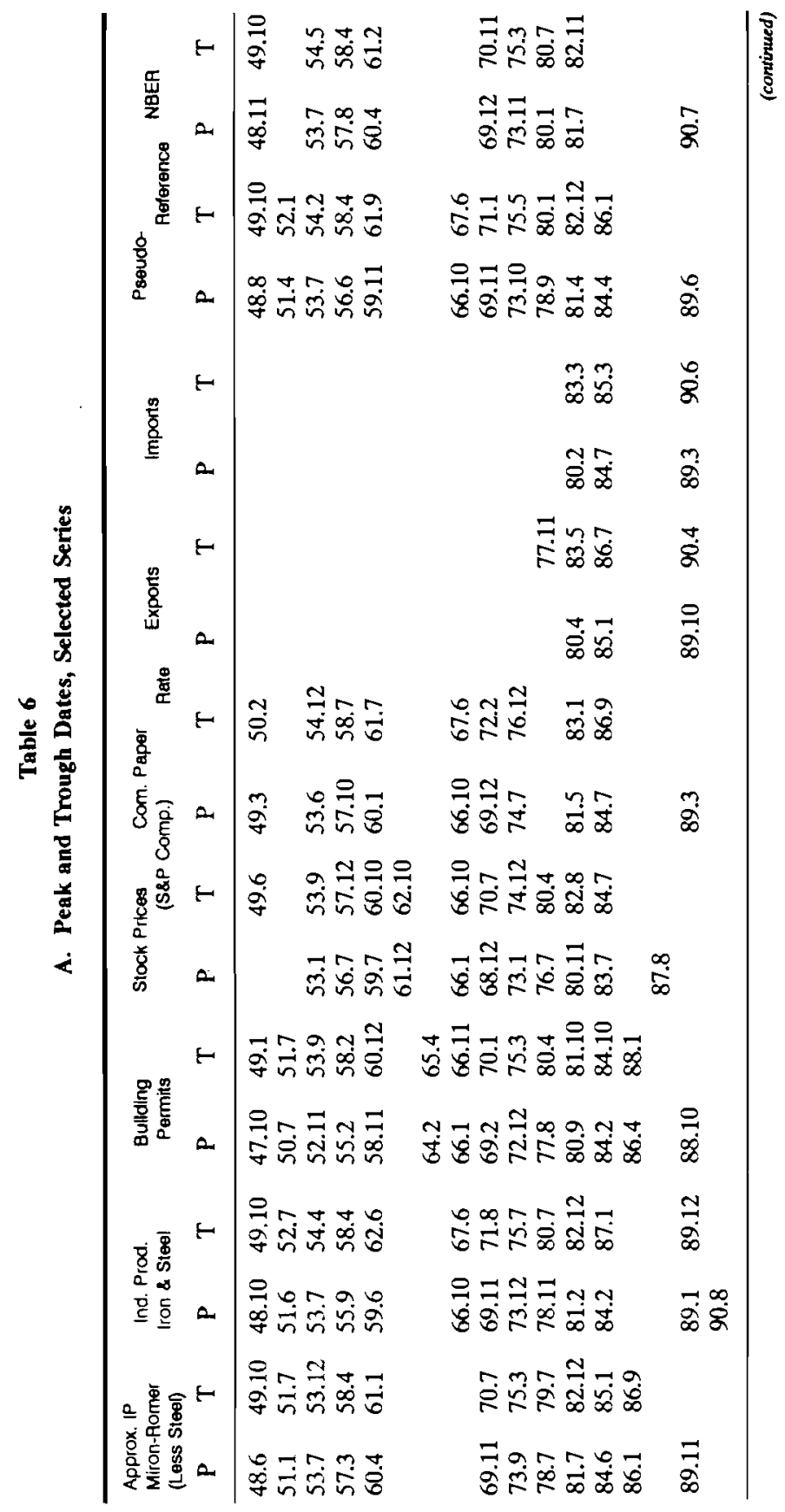




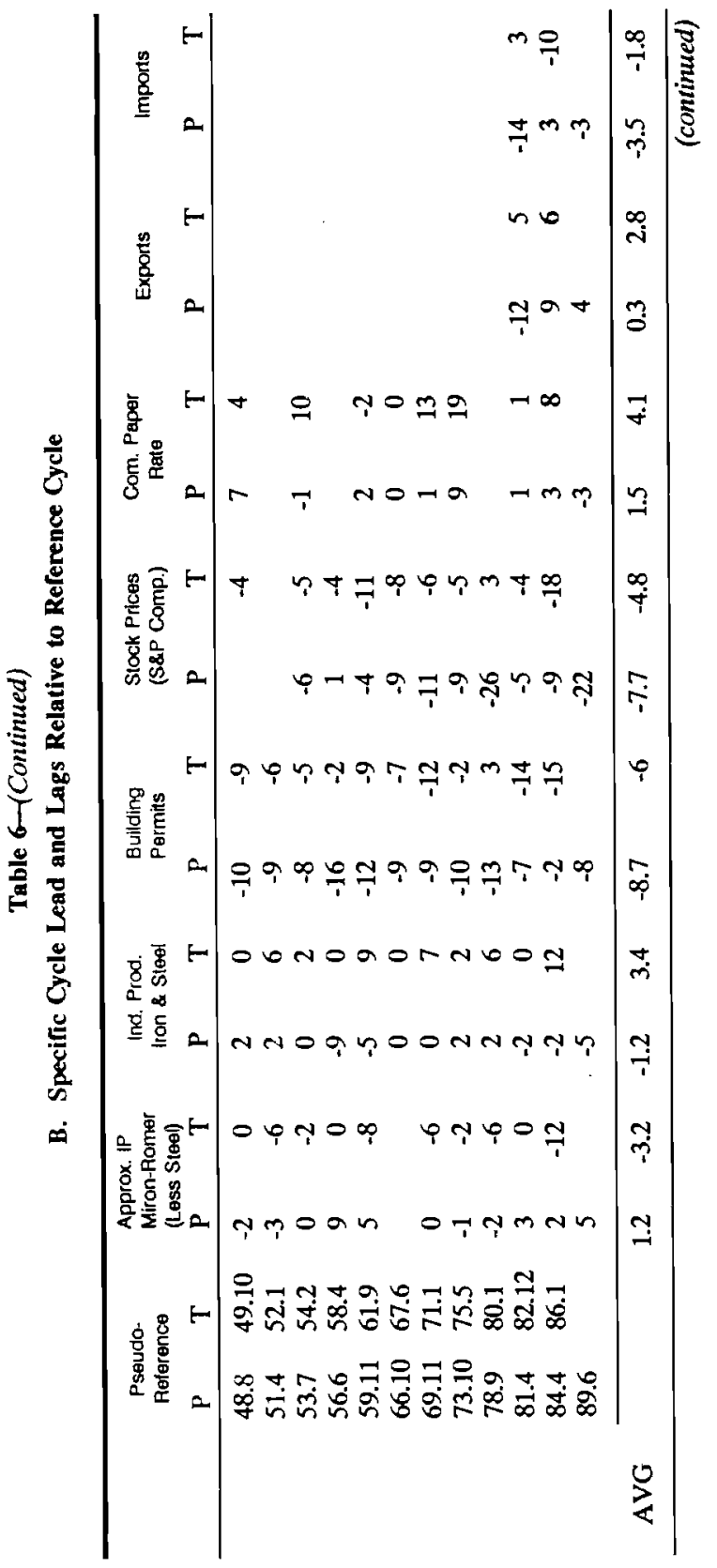




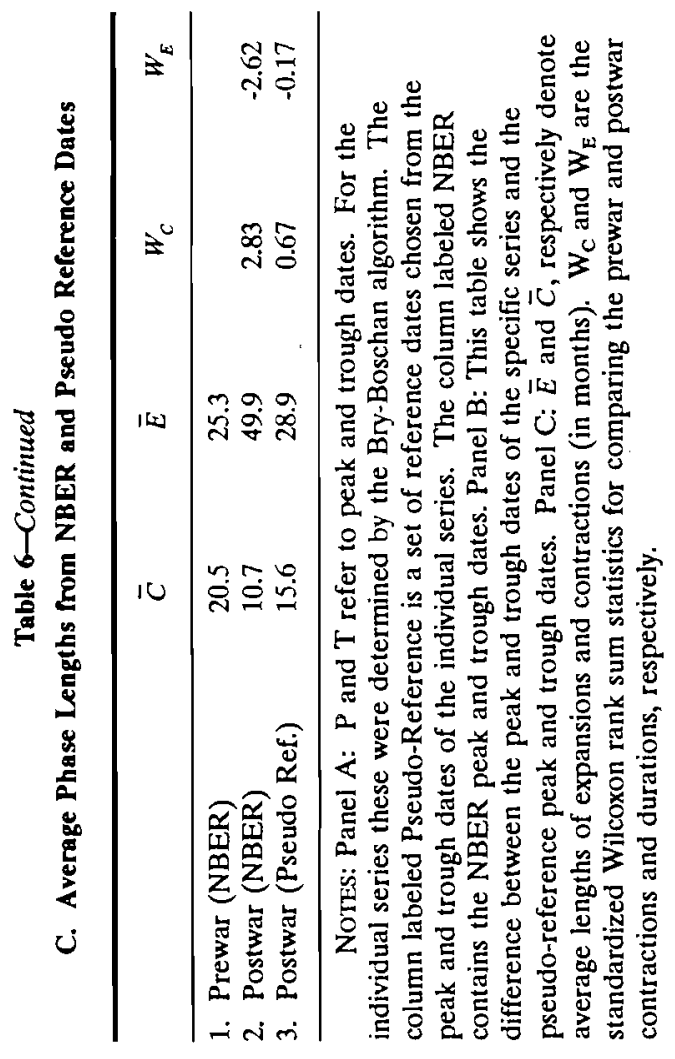




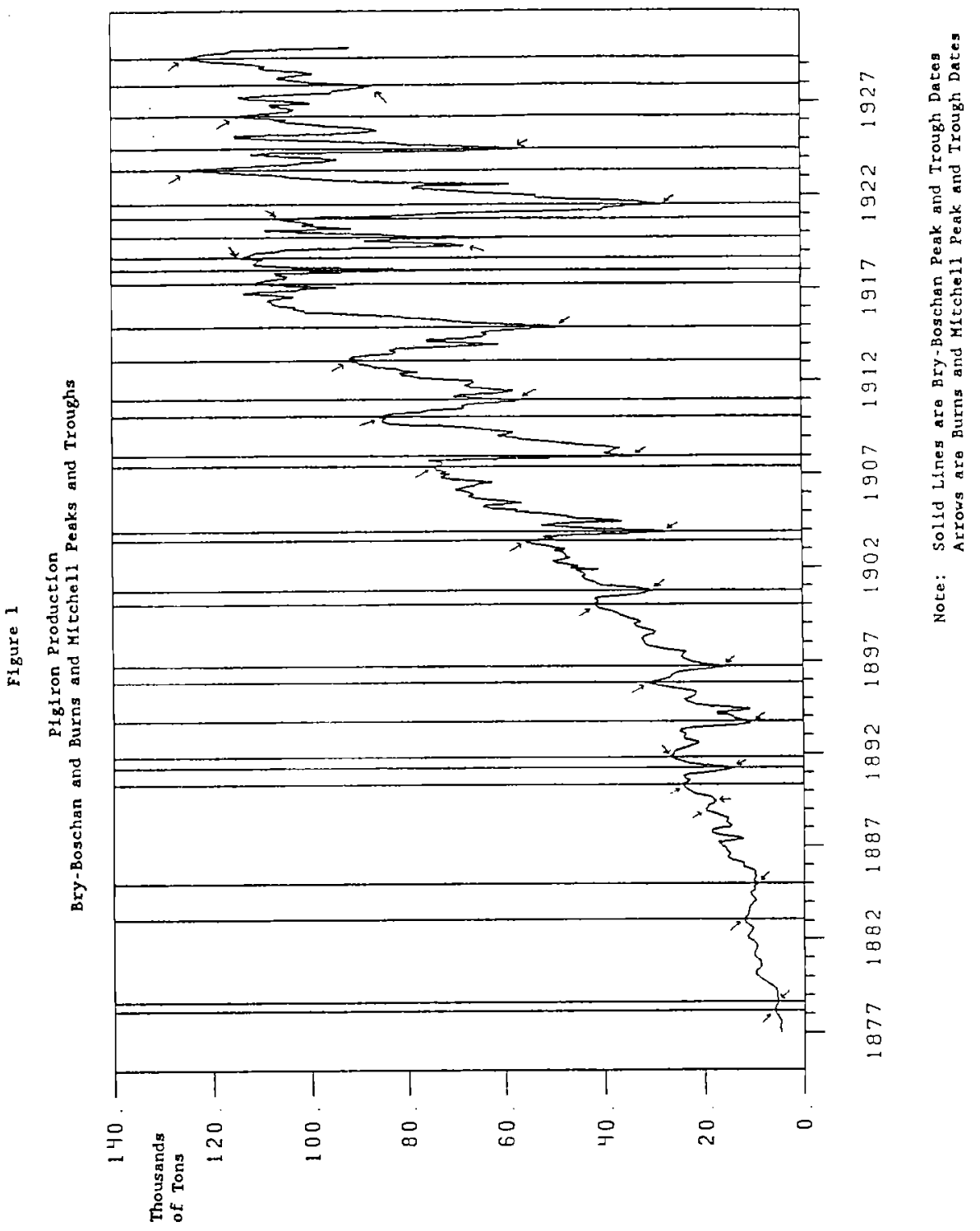

